\title{
Application of Instance Theory to Real-World Professional Vision: A Randomized Controlled Parallel Design in Clinical Psychology Education
}

\author{
Kenji Yokotani ${ }^{1}$, Seiya Mitani $^{2}$, Masako Okuno ${ }^{3}$, Keizo Hasegawa $^{4} \&$ Kohei Sato ${ }^{5}$ \\ ${ }^{1}$ Graduate School of Clinical Psychology, Niigata Seiryo University, Niigata, Japan \\ ${ }^{2}$ Center for Clinical Practice in Education, Aichi University of Education, Aichi, Japan \\ ${ }^{3}$ Faculty of Humanities and Social Science, Iwate University, Iwate, Japan \\ ${ }^{4}$ Graduate School of Education, Tohoku University, Miyagi, Japan \\ ${ }^{5}$ Faculty of Education, Art and Science, Yamagata University, Yamagata, Japan \\ Correspondence: Kenji Yokotani, Graduate School of Clinical Psychology, Niigata Seiryo University, 1-5939, \\ Suidocho, Chuo-ku, Niigata-shi, Niigata, 951-8121, Japan. Tel: 81-25-266-0127. E-mail: \\ yokotani@n-seiryo.ac.jp
}

Received: July 22, 2014

Accepted: September 9, $2014 \quad$ Online Published: October 15, 2014

doi:10.5539/jedp.v4n2p117

URL: http://dx.doi.org/10.5539/jedp.v4n2p117

\begin{abstract}
We aimed to extend instance theory into the domain of real-world professional vision development, examining the effects of explicit rules and exemplars on development of professional vision in a randomized controlled fashion. Participants were novice therapists $(N=48)$ attending accredited clinical psychology programs in Japan and were randomly divided into four training groups, which received (1) declarative knowledge-based and exemplar-based training, (2) declarative-based training only, (3) exemplar-based training only, and (4) no training. Before, during, and after the training, participants watched an authentic solution-focused brief therapy (SFBT) video and had five minutes to write down their notices regarding the video. Three expert therapists independently evaluated these notices in terms of relevance to SFBT. As hypothesized, novices who received both types of training showed increases in notice relevance during and after the training. In contrast to our hypothesis, novices who received exemplar-based training only showed increased notice relevance during the training. Declarative knowledge with exemplars could provide the best approach for the development of professional vision. Still, many self-motivated learners might learn professional vision in the absence of explicit teaching of declarative knowledge. Future studies should examine the link between participants' motivation and training effects of mere exposure to exemplars.
\end{abstract}

Keywords: instance theory, professional vision, clinical psychology, notice, solution-focused brief therapy

\section{Introduction}

\subsection{Professional Vision}

Acquisition of professional vision is essential for the novice who wishes to become a professional. Professional vision is defined as "socially organized ways of seeing and understanding events that are answerable to the distinctive interests of a particular social group" (Goodwin, 1994, p. 606). For example, health care staff have specific coding schemas to read mammograms such that they have a high specificity and sensitivity for prediction of patients' breast cancer, even though such individuals may not see the patients directly (Hartswood, Procter, Rouncefield, \& Slack, 2002). Most experts have a professional vision for their own fields, including individuals working in health care (Hartswood et al., 2002), law (Goodwin, 1994), education (Sherin \& Han, 2004), physics (Chi, Feltovich, \& Glaser, 1981), playing chess (De Groot, 1978), and geology (Goodwin, 1997). These studies suggest that professional vision is very common among experts. Because training of professional vision is fundamental for most professional groups, many such training programs have been developed, particularly in the fields of teacher (Sherin \& Van Es, 2009; Stürmer, Könings, \& Seidel, 2013; Van Es \& Sherin, 2002, 2008; See review, Borko, 2004; Cohen, Raudenbush, \& Ball, 2003; Putnam \& Borko, 2000) and health 
care education (Crowley, Naus, Stewart III, \& Friedman, 2003;.Naghshineh et al., 2008; Peterson, Vincent, \& Fechter-Leggett, 2011). Nevertheless, factors that contribute to the development of professional vision remain unclear. We applied instance theory (Logan, 1988, 2002; Palmeri, Wong, \& Gauthier, 2004) to the development of real-world professional vision and examined contributing factors. We formulated three hypotheses according to this theory and examined them through four types of training in a randomized controlled fashion.

\subsection{Training Programs for Professional Vision}

The achievement of professional vision is a fundamental aspect of professional training. From a professional learning standpoint (Putnam \& Borko, 2000), most programs share three core components. The first is declarative knowledge (Carpenter, Fennema, \& Franke, 1996; Simon \& Schifter, 1991), defined as general technical principles (Schneider, Rittle-Johnson, \& Star, 2011). For example, a clinical psychology textbook would serve as a source of declarative knowledge for clinical psychologists in training. The second component is exemplars, defined as model practice (Grossman, Wineburg, \& Woolworth, 2001; Stein, Smith, \& Silver, 1999). A supervisor's comment on a specific therapy intervention could be an exemplar for clinical psychologists. The third is recorded practice (Little, Gearhart, Curry, \& Kafka, 2003; Putnam \& Borko, 2000). For example, videotapes of therapy sessions constitute recorded practice for clinical psychologists. These three components are usually all integrated into recent educational programs (See Cohen, Raudenbush, \& Ball, 2003, for a review).

Previous findings suggest that those who view recorded practice and receive declarative knowledge with exemplars show enhanced professional vision (See Borko, 2004, for a review). For example, the teacher training program "Video Club" involves recorded video tapes by club members, general principled questions by a facilitator, and many exemplars provided by experienced teachers (Sherin \& Han, 2004). This video club enhances mathematics teachers' professional vision: Based on their detailed observations, trained teachers show an improved ability to choose effective coaching strategies according to individual students' needs (Van Es \& Sherin, 2008). Two such clubs conducted in different settings both showed beneficial effects on trainees' professional vision (Sherin \& Van Es, 2009). Along the same vein, the "Video Course" includes recorded video tapes depicting an experienced teacher, lectures on general teaching principles, and many specific exemplars also delivered in a lecture format (Stürmer et al., 2013). This course enhances pre-service teachers' professional vision, such that they can better predict whether students can study by themselves or whether they need more focused instruction, by observing the students in a classroom environment (Stürmer et al., 2013). Furthermore, supervisors' comments and declarative knowledge also enhance the visual diagnostic skills of medical students (Naghshineh et al., 2008). These findings imply positive links between combined declarative knowledge/exemplar-based training and professional vision.

\subsection{Instance Theory}

Instance theory can serve to clarify generalized and theoretical relationships between declarative knowledge, exemplars, and professional vision (Logan, 1988, 2002; Palmeri et al., 2004). According to instance theory (Logan, 1988, 2002) and its extended version (Nosofsky \& Palmeri, 1997; Palmeri et al., 2004), people interpret phenomena both by using explicit rules and retrieving an exemplar. Novices at first have insufficient experience with exemplars, such that they must rely on explicit rules (Logan, 1988). However, as individuals begin to store specific exemplar memories, they come to rely more on use of such memories, given that such retrieval becomes faster than rule use (Logan, 1988). Hence, by such logic, the development of professional vision initially requires acquisition of explicit rules as a primary step, with secondary reliance on exemplars of specific rule applications as such memories are acquired (Logan, 2002). Furthermore, professional vision is always a competitive choice between rule use and memory retrieval (Nosofsky \& Palmeri, 1997; Palmeri et al., 2004). Retrieval of an exemplar reflects the exemplar as the winner of the race. At the same time, other exemplars and rules become the losers. However, the losers of the race restrict the range that the winner can occupy: The more losers, the more severe such restriction. Those who develop their professional vision ultimately come to interpret phenomena with relatively limited variance. In sum, development of professional vision narrows the scope of viewpoints considered for a given situation, although quality of the resulting professional performance is enhanced (Nosofsky \& Palmeri, 1997; Palmeri et al., 2004).

According to instance theory, declarative knowledge is synonymous with explicit rules in the development of professional vision. Indeed, training explicit rules decreases the mean and standard deviation of reaction times for decisions as to whether a series of letters are presented in English or not (Logan, 1988), and a similar pattern occurs for categorization of several graphics (Erickson \& Kruschke, 2002; Nosofsky \& Palmeri, 1998). These studies suggest that training explicit rules affects professional vision. Similarly, repetitive exposure to many 
retrievable exemplars decreases reaction times for the categorization of several dots (Palmeri, 1997) and graphics (Nosofsky \& Palmeri, 1997), with similar decreases in reaction time variance. On the other hand, one study found that repetitive exposure to many exemplars was not effective when participants did not have access to explicit rules (Logan, 1988). In a real-world setting, repetitive exposure to bird pictures was not effective in helping participants to distinguish categories of birds when participants were not instructed to sort the birds into fine categories (Tanaka, Curran, \& Sheinberg, 2005). This pattern suggests that explicit rules are an initial requirement for the development of professional vision, with a possible role for specific exemplars later in the process.

Instance theory (Logan, 1988, 2002) and subsequent extensions (Nosofsky \& Palmeri, 1997; Palmeri et al., 2004) enjoy considerable support in laboratory settings involving university student populations and computer-based tasks but has been little applied to actual professional fields. Although instance theory enjoys support obtained via strictly controlled research designs, it is not clear that such principles will apply to self-motivated professional learners during professional training in real-world settings.

\subsection{Aims of the Present Study}

We aimed to apply instance theory to the scenario of self-motivated professional learners developing professional vision in a real-world setting. Self-motivated professional learners can be recruited through clinical psychology programs. Such programs are very competitive (percentage of acceptance is around 10\%) across the world (Kamizato, 2009; Norcross, Sayette, Mayne, Karg, \& Turkson, 1998), such that enrolled students and recent graduates of such programs can clearly be regarded as self-motivated professional learners. Solution-focused brief therapy (SFBT) was the specific therapy methodology examined here. SFBT emphasizes constructing solutions and helping clients to imagine how they would like things to be different, and what it will take to make that happen. Little attention is paid to diagnosis or history taking. SFBT assumes that clients have the capacity to change and that the change, or at least part of it, is probably already happening. Treatment is brief, usually lasting less than six sessions, and is conducive to video recording (Berg \& de Shazer, 2007/2008; Gingerich \& Eisengart, 2000; Hasegawa, Wakashima, Sato, Ikuta, Misawa, \& Kubo, 2002; Hoyt \& Berg, 2006).

To evaluate professional vision, we sampled participant notices while participants watched recorded practice. A notice involves identifying what is important in a specific situation and making connections between the specific situation and broader principles in one's own field (Van Es \& Sherin, 2002), such that participant notices can be regarded as a core aspect of an individual's professional vision (Stürmer et al., 2013; Sherin \& Van Es, 2009; Van Es \& Sherin, 2002, 2008). The relevance of participant notices has also been evaluated from professional perspectives. Although several categories of notice have been suggested, these categories were specifically designed for teachers (Star \& Strickland, 2008; Stürmer et al., 2013; Van Es \& Sherin, 2008). Hence, direct utilization of these categories was not particularly feasible for psychotherapists in training. Our study utilized a notice evaluation approach (Kersting, 2008; Stürmer et al., 2013) but categories of notice were not applied. Here, participant notices were evaluated by professionals from the perspective of SFBT. Relevance to SFBT was regarded as an indicator of professional vision development/quality. Number of notices provided was regarded as indicative of the scope of their vision. Furthermore, their academic, clinical and self-reflective experience were evaluated because these experiences might be expected to affect professional vision (e.g., Carpenter, Escudero, \& Rivett, 2008; Trepka, Rees, Shapiro, Hardy, \& Barkham, 2004).

According to instance theory (Logan, 1988, 2002) and subsequent revisions (Nosofsky \& Palmeri, 1997; Palmeri et al., 2004), we formulated three main hypotheses. First, declarative knowledge-based training should increase the quality of professional vision while narrowing scope of the vision. Declarative knowledge of psychotherapy is fundamental to the development of clinical psychologists (Peterson et al., 2011) and specific knowledge about disorders helps prevent psychologists from holding biased views toward clients with such disorders (Kemp \& Mallinckrodt, 1996). Specific hypotheses are as follows. Hypothesis 1 (H1): Novices who receive declarative knowledge-based training would show higher notice relevance but a reduced number of notices as compared to those who did not receive any training. Second, according to these theories (Logan, 1988, 2002; Nosofsky \& Palmeri, 1997; Palmeri et al., 2004), declarative knowledge-based training with exemplars should increase quality of professional vision while narrowing the scope of the vision. Several studies have found that declarative knowledge with exemplars improves professional vision and therapeutic behaviors (Henry, Strupp, Butler, Schacht, \& Binder, 1993) and enhances therapeutic treatment effects (Stein, \& Lambert, 1995), with a few exceptions (Christensen \& Jacobson, 1994). Hypothesis 2-1 (H2-1): Novices who receive both declarative knowledge-based training and exemplar-based training would show higher notice relevance but provide fewer 
notices than those who did not receive any training. Furthermore, we hypothesized that exemplar-based training would have an additive benefit on declarative-based training. Hence, hypothesis 2-2 (H2-2): Novices who receive both types of training would show higher notice relevance but fewer notices than those who received declarative-based training only. However, exemplar based training alone should not yield beneficial effects in the absence of explicit rules (Logan, 1988; Tanaka et al., 2005). Hypothesis 3 (H3): Novices who receive exemplar-based training only would not show significant differences for their notices in terms of relevance and number during or after the training.

\section{Method}

\subsection{Participants}

Eligibility criteria for participants were (a) those who were studying in an accredited graduate school of clinical psychology in Japan or (b) those who had graduated from such a school in the past 5 years. Fifty-three Japanese novice therapists were recruited during April to November 2011 through clinical psychology programs at A (Tohoku, North East), B (Hokuriku, North West), C (Hokuriku, North West), and D (Chubu, Midland) universities. The Japanese Association for Graduate Programs in Clinical Psychology accredited all programs. Five therapists were excluded from our analysis: Four had schedules that were difficult to accommodate; the finale participant $(n=1)$ was excluded to make group sizes equivalent. Hence, data from forty-eight Japanese novice therapists were analyzed. Thirty-four participants were female and the other 14 were male. Average participant age was 27.0 years $(S D=8.1, \max =62, \min =22)$. Thirty-one participants were in the process of completing Master's degrees and 17 participants were recent graduates. Three of these 17 participants were working on their doctorates. Ten of the recent graduates worked as therapists in medical and educational facilities while the other four were conducting research. Average years of clinical experience was $0.7(S D=1.2$, $\max =5, \min =0$ ). Average number of supervised cases was $2.8(4.2)$. Six participants were oriented toward SFBT. All participants received an explanation of the experimental procedure and signed a letter of informed consent. Participants were paid 2500 yen (about 25 US dollars) for their participation. The ethics committee at B University approved the present study protocol.

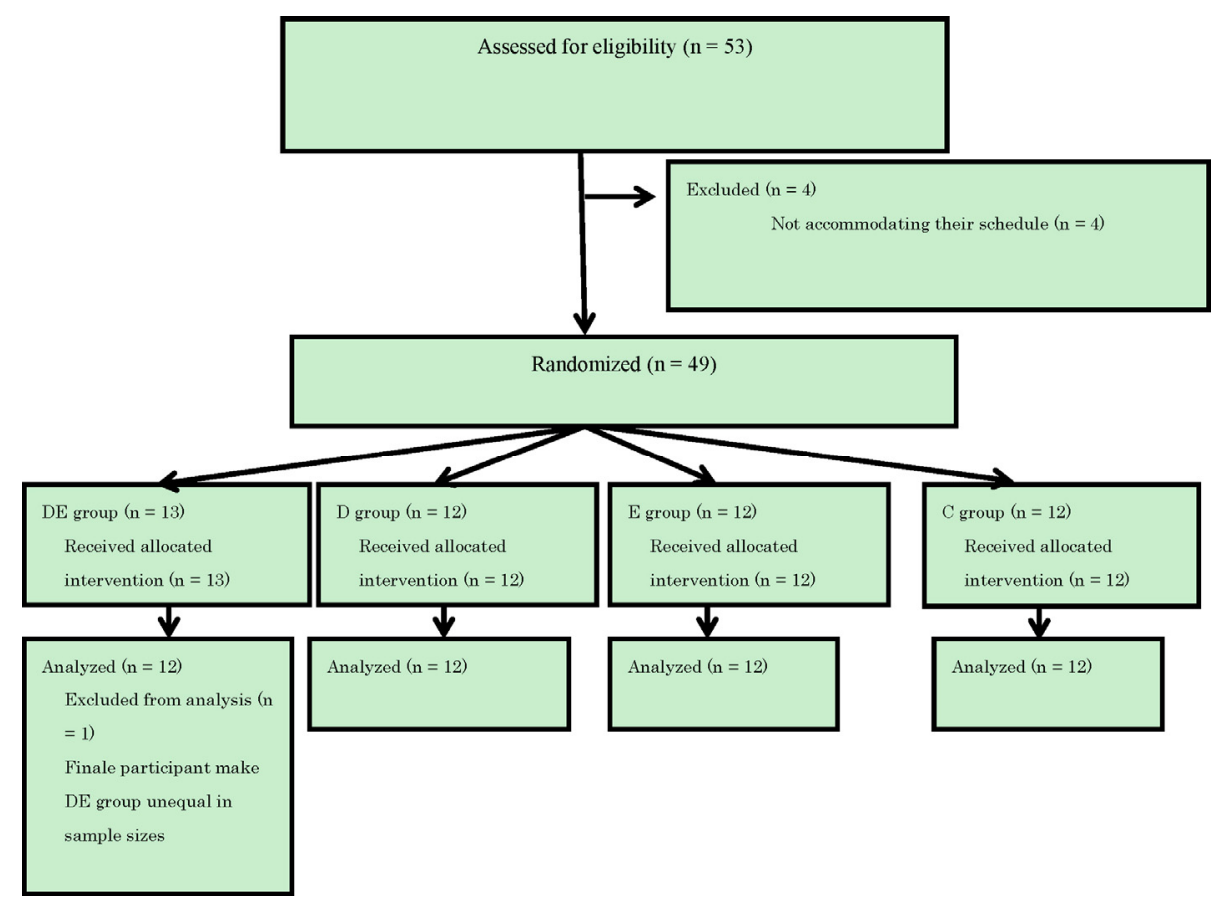

Figure 1. Participant flow diagram

Note. DE: Declarative knowledge and Exemplar-based training group, E: Exemplar-based training group, D: Declarative knowledge-based training group, C: Control group. 


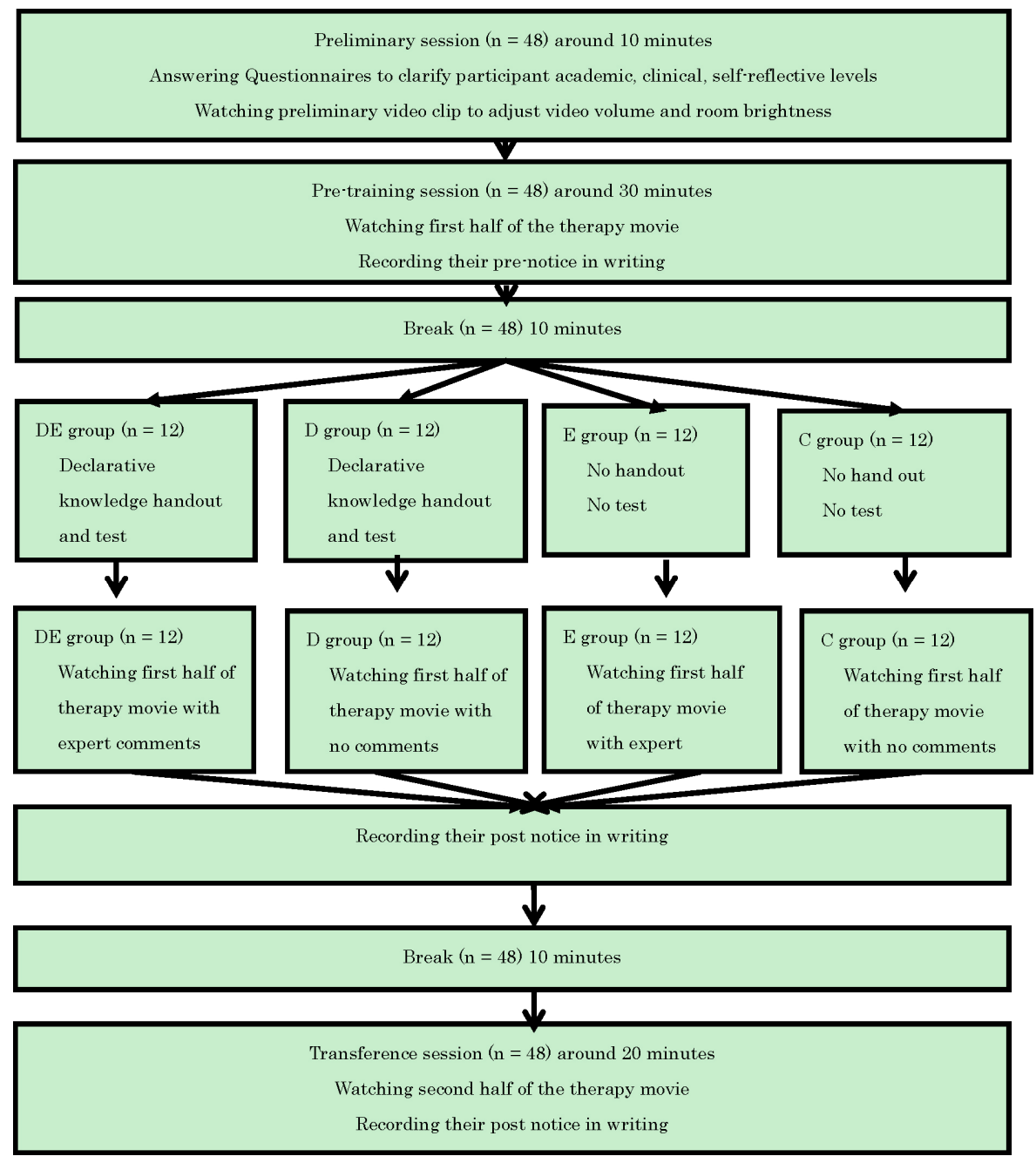

Figure 2. Experimental procedure

Note. DE: Declarative knowledge and Exemplar-based training group, E: Exemplar-based training group, D: Declarative knowledge-based training group, C: Control group.

\subsection{Procedure}

Experimental sessions were conducted in a therapy room at B University as well as in laboratories at A and D universities. All sessions were conducted individually. Twelve participants were randomly assigned to each of four groups in a parallel design (See Figure 1): Declarative knowledge and exemplar-based training (DE), declarative knowledge-based training only (D), exemplar-based training only (E), or control/no training (C). Participants completed a questionnaire during a preliminary session to assess participants' academic levels, clinical experience, and tendencies to be self-reflective (See Figure 2). Participants then watched the 30-second preliminary video clip, adjusting video volume and room brightness as needed.

During the pre-training session, participants were asked to think aloud while they were watching the movie (Figure 2). They were also instructed to formulate the case depicted in the movie (conceptualization of the client from a clinical psychology perspective) and to plan a therapy program for the case (clarification of the therapeutic structure and methods): Case formulation and therapy program were written down after participants watched the full movie. These instructions were intended to motivate participants to assess and to solve the client's problems from a professional perspective. Participants watched the first half of the therapy movie, with the experimenter leaving the room. They could take notes while watching the movie. After they watched the movie, participants were given up to five minutes to record their notices in writing, on the basis of their notes 
and memory. These notices were referred to as pre-notices. Participants then took a 10-minute break during which they were not permitted to read.

During the training session, the DE, D, and E groups received either or both declarative knowledge-based and exemplar-based training. In the declarative knowledge-based training, participants studied a declarative knowledge handout (see below), after which they had to answer two multiple-choice questions about SFBT, each with four response options. Participants were asked to explain incorrect choices, which were then followed by further explanation provided by the experimenter. The declarative knowledge-based training was completed when participants successfully answered both questions. Those who did not receive declarative knowledge-based training did not receive the handout or questions.

In the exemplar-based training, participants watched the first half of the therapy movie along with expert commentary. They then rated whether they could hear the expert commentary on a 5-point scale (1 Strongly Disagree, 2 Disagree, 3 Uncertain, 4 Agree, 5 strongly Agree). They all agreed or strongly agreed $(M=4.5, S D=$ 0.5 , $\operatorname{Min}=4, \operatorname{Max}=5$ ). Groups without exemplar-based training watched the first half of the therapy movie but without expert commentary (See Figure 2).

After the training, participants were given up to five minutes to record their new notices in writing. They were not allowed to write the same things that they had previously written. These notices were referred to as post notices. During the transference session, all participants watched the second half of the therapy movie and wrote down new notices. Again, they were not allowed to record the same things they had previously written. These notices were referred to as transference notices.

\subsection{Materials}

\subsubsection{Preliminary Video Clip}

A Windows 7 wildlife video was used. The video clip shows wild animals in natural settings with music and lasts 30 seconds (Microsoft Corporation, 2009).

\subsubsection{Therapy Movie}

This was titled "I want to want to...." and features Japanese subtitles (Berg \& deShazer, 2007/2008). The movie showed an SFBT session: The client was a young male paraplegic whose disability was caused by a car accident. The therapist was Steve de Shazer, one of the founders of SFBT (e.g., Gingerich \& Eisengart, 2000). The first half of the therapy movie lasts 24 minutes and 54 seconds. The second half of the movie lasts 12 minutes and 12 seconds. All participants watched the movie for the first time.

\subsubsection{Exemplar}

An expert therapist who is a pioneer of Japanese SFBT and family therapy (Hasegawa et al., 2002) simultaneously commented on the first half of the therapy movie, with the comments previously recorded and synchronized with the movie. Expert audio commentary was provided to participants, as recommended by Van Gog, Paas, and Van Merriënboer (2006). For video playback, an eME732Z-F22B laptop and SENNHEISER / HD380PRO headphones were used. An Olympus Voice Trek V-75 GRY IC recorder and an Audio-Technica AT9901 microphone were used to record the expert commentary. Windows Movie Maker 2.6 was used for video editing.

\subsubsection{Declarative Knowledge}

"Case studies in couple and family therapy" (Hoyt \& Berg, 1998/2006) was selected as a source of declarative knowledge. The first author of the present paper, an expert in SFBT, shortened the relevant text from 24 pages to 4 pages to enhance readability. This shortened version was comprised of an introductory section (pp.215-217), concluding section (pp. 236-238), and authors' comments on a case (pp. 218-236): Case details (pp. 218-236) were omitted. Conceptual maps (e.g., Nesbit \& Adesope, 2006; See Appendix A) including SFBT principles and practice guidelines were added to promote participants' understanding of SFBT. Participants were also told that parts of the declarative knowledge reflect standard therapy practice whereas other elements are specific to SFBT. Two questions were administered to check participants' understanding of the material (See Appendix B).

\subsection{Measures}

\subsubsection{Number of Notices}

Before, during, and after the training sessions, participants received a sheet of A4-size white paper with 11 answer bullets and the following instructions: "If you notice anything in the video, please write down what you 
notice by one of the bullets". They were then given up to five minutes to record their notices in writing. This procedure was followed even if participants had nothing to write down. When they did not use all 11 answer bullets, they were asked to group their sentences so that we could determine whether a given sentence was a separate comment or just an elaboration on something said previously. All told, 733 separate notices were sampled.

\subsubsection{Notice Relevance}

The 733 notices were transcribed into a Word document so that specific handwriting could not be identified. Three SFBT experts evaluated the notices. Two were male and one was female; all were clinical psychologists. All had Ph.D. degrees and tenure-track positions (one professor, one associate professor, and one lecturer) at accredited graduate programs in clinical psychology. Their average age was 47.6 $(S D=14.2, \max =60, \min =$ $32)$, their average years of clinical experience was $23.6(S D=11.2, \max =35.5, \min =13)$, and their average years of SFBT clinical experience was $12.6(S D=6.4, \max =20, \min =8)$. All three experts rated each notice in terms of relevance to SFBT on a 7-point scale $(1=$ of no relevance to SFBT, $7=$ of extreme relevance to SFBT). The internal consistency of their ratings was high (Cronbach's alpha $=.79$ ), such that relevance of participant notices was obtained by averaging across the three experts.

\subsubsection{Index of Clinical Levels}

Participants provided information about their clinical experience. Definitions and computational methods for clinical experience followed the approach of the Foundation of the Japanese Certification Board for Clinical Psychologists (2004). Clinical experience was defined as clinical psychological assessment, therapy, and community support on the basis of advanced knowledge and skills acquired in undergraduate and graduate programs. Clinical experience needs to be paid, such that volunteer or other unpaid work was not regarded as such. Those who had worked more than 3 days per week reported their years of continuous employment as their period of clinical experience. Those who worked less than 3 days per week reported half their years of employment as their period of clinical experience.

\subsubsection{Index of Academic Level}

Participants specified whether they had completed bachelor's degrees and if so, provided their majors: Clinical psychology, general psychology other than clinical psychology, and any fields other than general psychology. Masters' and doctoral degrees were also specified and categorized in the same fashion.

\subsubsection{Self-Reflection Index}

Participants completed the Japanese version of the Rumination-Reflective questionnaire [RRQ] (Takano \& Tanno, 2008; Trapnell \& Campbell, 1999). The RRQ consists of 24 items anchored with 5-point scales. There are two sub-categories: Rumination (12 items) and reflection (12 items). Rumination is defined as dispositional self-attentiveness caused by negative emotionality (e.g., "I always seem to be rehashing in my mind recent things I've said or done"). Reflection is dispositional self-attentiveness motivated by intellectual interests (e.g., "I often love to look at my life in philosophical ways"). Previous studies of English and Japanese samples found that rumination had significant positive correlations with depressive symptoms and neuroticism, whereas reflection is positively correlated with personal openness (Takano \& Tanno, 2008; Trapnell \& Campbell, 1999). Alpha coefficients for rumination and reflection in the present study were .81 and .84 , respectively. These compare favorably with those identified in a previous study that sampled university students (Takano \& Tanno, 2008; .89 and .89 , respectively).

\subsection{Statistical Analysis}

We used multiple analyses of variance (MANOVA) to control for covariates. To evaluate group differences, (multiple) analyses of covariance (ANCOVA /MANCOVA) were used. The Bonferroni method was used for multiple comparisons. We also utilized four indexes to evaluate group differences as a function of the intervention (Rausch, Maxwell, \& Kelley, 2003): Change from pre to post notices [Post score - Pre score], change from pre to transference notices [Transference score - Pre score], change from post to transference notices, [Transference score - Pre score], and total change after the training [(Transference score + Post score)/2]. Each score has two categories (relevance and number), such that these four indices involve eight scores in total. 


\section{Results}

\subsection{Preliminary Analysis}

Table 1 shows descriptive data for the participant sample. There were no group differences in terms of participant age, clinical experience, or reflective scores. Table 1 also shows pre-notice data. There were no significant differences between the four groups on either the relevance or number of pre-notices. These data suggest that preexisting group differences do not explain subsequent group differences as a function of training.

\subsection{Training Differences in Participant Notices}

We conducted MANOVA to examine covariates of relevance and number of both post and transference notices. The independent variables were participant traits (Table 1) and relevance and number of pre notices. We found that participant age significantly affected post notice relevance, $F_{(1,34)}=5.1, p<.05$. Bachelor of clinical psychology degree also affected number of post notices, $F_{(1,34)}=6.1, p<.05$. Because neither index interacted significantly with training groups $\left(F_{(3,28)}=0.2\right.$, n.s.; $F_{(3,28)}=1.0$, n.s., respectively), we assumed that regression slopes for both indexes to the post notices were parallel to those of training differences. We therefore included participant age and bachelor of clinical psychology as covariates on the post notices. We also included pre notices as a covariate in all models.

To decrease the risk of type 1 errors, we used MANCOVA to assess training differences for notice variables on the whole (Dependent variables were post and transference notices. Covariates were pre notices, participant age, and bachelor of clinical psychology. Independent variable was training). MANCOVA revealed that all models were significant for the post notices $\left(F_{(7,40)}=5.6, p<.001\right)$ and transference notices $\left(F_{(7,40)}=2.3, p<.05\right)$ in term of relevance, and for the post notices $\left(F_{(7,40)}=4.7, p<.01\right)$ in term of number, but not for number of transference notices $\left(F_{(7,40)}=1.3, n . s\right.$. $)$. As expected, training differences broadly affected post and transference notices.

Table 1. Participant traits for each group

\begin{tabular}{|c|c|c|c|c|c|c|c|c|c|c|}
\hline & \multirow{2}{*}{\multicolumn{2}{|c|}{$\begin{array}{l}\mathrm{DE} \\
n=12\end{array}$}} & \multirow{2}{*}{\multicolumn{2}{|c|}{$\begin{array}{l}\mathrm{D} \\
n=12\end{array}$}} & \multirow{2}{*}{\multicolumn{2}{|c|}{$\begin{array}{l}\mathrm{E} \\
n=12\end{array}$}} & \multirow{2}{*}{\multicolumn{2}{|c|}{$\begin{array}{l}\text { C } \\
n=12\end{array}$}} & \multirow{2}{*}{\multicolumn{2}{|c|}{$\begin{array}{l}\text { Total } \\
n=48\end{array}$}} \\
\hline & & & & & & & & & & \\
\hline & $M$ & $S D$ & $M$ & $S D$ & $M$ & $S D$ & $M$ & $S D$ & \multicolumn{2}{|c|}{$M S D$} \\
\hline Age & 25.0 & 2.6 & 28.0 & 11.4 & 27.1 & 8.1 & 28.0 & 8.7 & 27.1 & 8.1 \\
\hline $\begin{array}{l}\text { Clinical } \\
\text { experience }\end{array}$ & 1.0 & 1.8 & 0.6 & 1.2 & 0.7 & 1.2 & 0.2 & 0.5 & 0.7 & 1.3 \\
\hline Rumination & 45.5 & 6.2 & 41.0 & 5.6 & 40.5 & 6.8 & 39.3 & 4.6 & 41.6 & 6.1 \\
\hline Reflection & 46.1 & 8.1 & 42.1 & 6.8 & 42.5 & 7.3 & 42.5 & 6.8 & 43.3 & 7.2 \\
\hline $\begin{array}{l}\text { Relevance of } \\
\text { pre notices }\end{array}$ & 4.6 & 0.6 & 4.4 & 0.8 & 4.6 & 0.9 & 4.4 & 0.7 & 4.5 & 0.7 \\
\hline \multirow{2}{*}{$\begin{array}{l}\text { Number of pre } \\
\text { notices }\end{array}$} & 5.6 & 1.8 & 5.8 & 2.5 & 5.8 & 2.3 & 5.6 & 1.8 & 5.7 & 2.0 \\
\hline & \multicolumn{2}{|l|}{$\%$} & \multicolumn{2}{|l|}{$\%$} & \multicolumn{2}{|l|}{$\%$} & \multicolumn{2}{|l|}{$\%$} & \multicolumn{2}{|l|}{$\%$} \\
\hline Male & \multicolumn{2}{|l|}{25} & \multicolumn{2}{|l|}{25} & \multicolumn{2}{|l|}{33} & \multicolumn{2}{|l|}{33} & \multicolumn{2}{|l|}{29} \\
\hline B.A. Cli. Psy & \multicolumn{2}{|l|}{42} & \multicolumn{2}{|l|}{33} & \multicolumn{2}{|l|}{33} & \multicolumn{2}{|l|}{58} & \multicolumn{2}{|l|}{42} \\
\hline M.A. Cli. Psy & \multicolumn{2}{|l|}{25} & \multicolumn{2}{|l|}{50} & \multicolumn{2}{|l|}{33} & \multicolumn{2}{|l|}{42} & \multicolumn{2}{|l|}{38} \\
\hline SFBT & \multicolumn{2}{|l|}{8} & 25 & & 8 & & 8 & & 12 & \\
\hline
\end{tabular}

Note. DE: Declarative knowledge and Exemplar-based training group, E: Exemplar-based training group, D: Declarative knowledge-based training group, C: Control group, SV: Supervision, SFBT: Solution-Focused Brief Therapy, B.A: Bachelor of Arts degree, M.A.: Master of Arts degree, Cli. Psy: Clinical Psychology. 


\subsection{Relevance of Participant Notices}

All three training group outperformed the control group with no robust difference between them during the training. D alone and $\mathrm{E}$ alone were not better than control during the transference session, whereas DE was (Figure 3).

We used ANCOVA to examine training effects on notices during the training session. As expected, training significantly affected relevance of post notices $\left(F_{(3,42)}=12.0, p<.001\right.$, Figure 3$)$. As hypothesized (H1 and $\mathrm{H} 2-1$ ), post notices for DE and D training groups improved significantly during the training session (paired $t=$ $4.5, d f=11$, adjusted $p<.01$; paired $t=4.3, d f=11$, adjusted $p<.01$, respectively) and attained significantly higher relevance than those of the control $\left(F_{(5,42)}=7.6, p<.001\right.$, Adjusted $R^{2}=.41, \mathrm{C}<\mathrm{DE}[d=1.69], \mathrm{C}<\mathrm{D}[d$ $=1.50]$ ). Figure 3 also shows that the ANCOVA model explained around $71 \%$ of the change from pre to post notices (dependent variable is relevance of post notices - relevance of pre notices. $F_{(5,42)}=24.1, p<.001$, Adjusted $\left.R^{2}=.71, \mathrm{C}<\mathrm{DE}[d=0.87], \mathrm{C}<\mathrm{D}[d=0.89]\right)$. On the other hand, post notices for DE were not significantly different from those for D: H2-2 was not supported. Furthermore, in contrast to H3, post notices for E training improved significantly during the training session (paired $t=3.6, d f=11$, adjusted $p<.05$ ) and attained significantly higher relevance than those of the control $(\mathrm{C}<\mathrm{E}[d=1.66])$.

During the transference session, training significantly affected relevance of transference notices $\left(F_{(3,43)}=3.1, p\right.$ $<.05$, Figure 3). An ANCOVA model explained $59 \%$ of the change from pre to transference notices $\left(F_{(4,43)}=\right.$ $18.4, p<.001$, Adjusted $R^{2}=.59$ ). As expected, transference notices for both DE and D training improved significantly after the training session (paired $t=4.4, d f=11$, adjusted $p<.01$; paired $t=3.7, d f=11$, adjusted $p$ $<.05$, respectively), but only the DE training group attained significantly higher relevance than the control group $\left(F_{(4,43)}{ }^{\mathrm{b}}=3.7, p<.05\right.$, Adjusted $\left.R^{2}=.18, \mathrm{C}<\mathrm{DE}[d=1.20]\right)$. $\mathrm{H} 3$ was supported, but $\mathrm{H} 2-2$ was not supported. Interestingly, the control group showed an improvement after the training session with significant tendency (paired $t=2.5, d f=11$, adjusted $p=.08$ ).

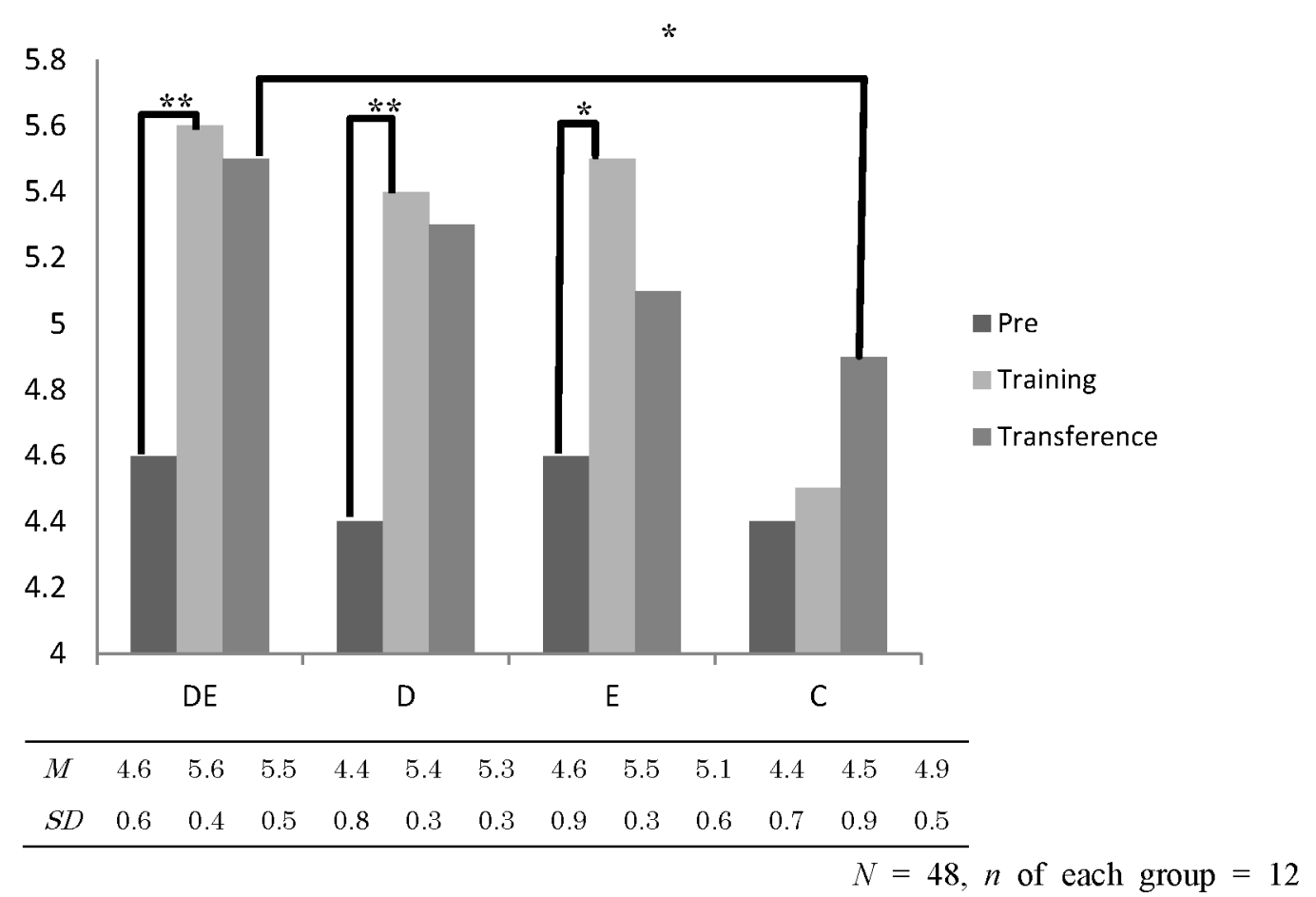

Figure 3. Enhancement of professional vision during training

Note. DE: Declarative-based and Exempla-based training group, D: Declarative-based training group, E: Exemplar-based training group, C: Control group, Pre: Pre-training session, Training: Training session, Transference: Transference session, ${ }^{* *}: p<.01, *: p<.05$. 


\subsection{Number of Participant Notices}

The scope of vision in DE and D groups was narrower than the scope in E group during the training. The differences between four groups were disappeared during training session (Figure 4).

We used ANCOVA to examine training effects on number of post notices. As expected, training significantly affected number $\left(F_{(5,42)}=6.2, p<.001\right.$, Adjusted $R^{2}=.36$, Figure 4$)$. As hypothesized (H1 and H2-1), post notices for both $\mathrm{DE}$ and $\mathrm{D}$ training decreased significantly during the training session (paired $t=3.2, d f=11$, adjusted $p<.05$; paired $t=3.7, d f=11$, adjusted $p<.01$, respectively) but did not attain significantly narrower scope than those of the control group. These data did not support H1, H2-1, or H2-2, but did support H3.

During the transference session, training did not affect number of transference notices (Figure 4). An ANCOVA model explained $56 \%$ of the change from pre to transference notices (dependent variable is the number of pre notices - the number of transference notices. $F_{(4,43)}=16.5, p<.001$, Adjusted $R^{2}=.56$ ), but training type did not explain these differences. These data did not support H1, H2-1, or H2-2, but supported H3.

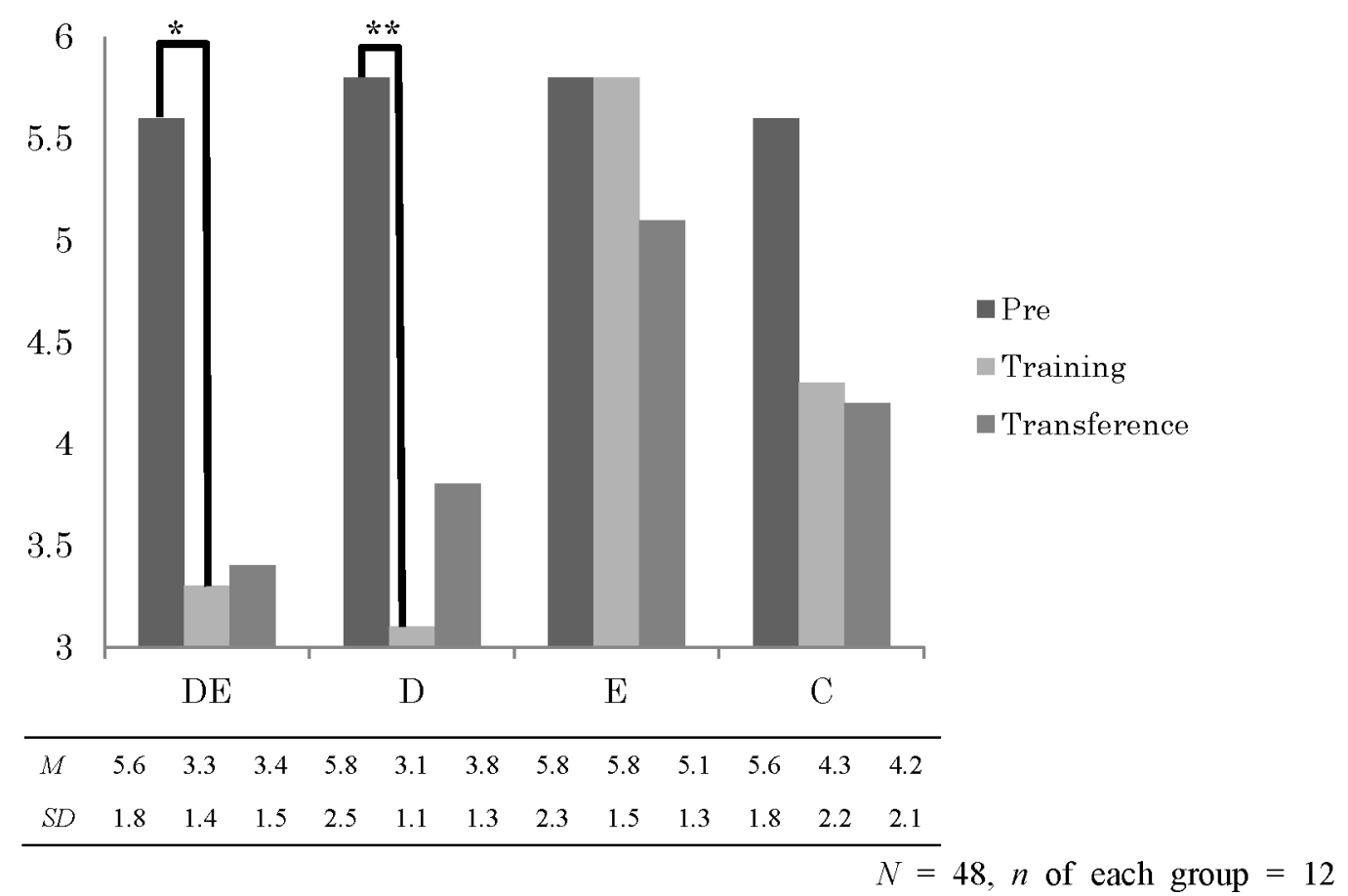

Figure 4. Decrease in number of notices during training

Note. DE: Declarative-based and Exempla-based training group, D: Declarative-based training group, E: Exemplar-based training group, C: Control group. Pre: Pre-training session, Training: Training session, Transference: Transference session. ${ }^{* *}: p<.01, *: p<.05$.

\section{Discussion}

\subsection{Applicability of Instance Theory into Clinical Psychologists' Professional Vision}

Our study applied instance theory (Logan, 1988, 2002; Nosofsky \& Palmeri, 1997; Palmeri et al., 2004) to the domain of real-world professional vision. As hypothesized, provision of declarative knowledge enhanced participants' professional vision during a training session. Although declarative knowledge-based training only did not enhance professional vision after the training, those who received both declarative knowledge-based training and exemplar-based training showed enhanced professional vision not only during the training session but also after the training. These findings suggest that provision of declarative knowledge and exemplars have more sustained effects on professional vision than does provision of declarative knowledge only. These findings directly supported $\mathrm{H} 1$ and $\mathrm{H} 2-1$ and indirectly supported H2-2. These findings are consistent with instance theory (e.g., Erickson \& Kruschke, 2002) and previous findings in the professional development (Borko, 2004; 
Carpenter et al., 1996; Cohen et al., 2003; Putnam \& Borko, 2000; Simon \& Schifter, 1991) and clinical psychology training (Henry et al., 1993; Kemp \& Mallinckrodt, 1996; Peterson et al., 2011; Stein, \& Lambert, 1995) literatures. Our findings support the generalizability of instance theory to the domain of real-world professional vision. The use of a randomized controlled parallel design in the present study also provides robust verification of the theory.

On the other hand, our hypotheses were not well supported in terms of scope of professional vision. As expected, $\mathrm{D}$ and DE training decreased participant notices during the training, although these effects disappeared after the training, even though the number of notices remained small (Figure 4). Furthermore, the number of notices from these training groups was not significantly different from those of the control group during and after the training. These findings are not consistent with instance theory (Logan, 1988, 2002; Nosofsky \& Palmeri, 1997; Palmeri et al., 2004). These data can be interpreted in two ways. First, number of notices might be linked with participant motivation to acquire professional vision (e.g., Sherin \& Han, 2004; Sherin \& Van Es, 2009; Van Es \& Sherin, 2008). Such professional motivation might offset training effects on scope of notice. Second, the control group showed an unexpected improvement in their professional vision. Hence, the gap between $\mathrm{DE} / \mathrm{D}$ and control groups might be too small to show a significant difference.

\subsection{Effects of Exemplars on Real-World Professional Vision}

In a laboratory setting, mere exposure to exemplars was ineffective to develop expertise unless experimenters taught participants explicit rules (Logan, 1988) or instructed them to use detailed categories (Tanaka et al., 2005). On the other hand, our study found that participants who received exemplar-based training only did show enhanced professional vision during the training session. Professional vision quality was significantly higher as compared to this groups' counterparts in the control group, although this effect were not sustained after the training session. Otherwise, in real-world settings, mere exposure to exemplars was effective to develop participants' professional vision for short time, even though trainers in these studies neither taught explicit rules nor instructed participants to use specific categories (Grossman et al., 2001; Stein et al., 1999). Inconsistencies between laboratory and real-world findings might stem from participants' self-motivated learning style. Our participants were all self-motivated professional learners (Kamizato, 2009; Norcross et al., 1998) who are more likely to push themselves to learn, which are rare in laboratory samples. The differences of these learning styles might affect the development of professional vision.

Self-motivated participants might extract explicit rules from exemplars, even though they did not receive explicit instruction. Because of their high motivation, such individuals might try to capitalize on any learning resources that they can, such that they might try to obtain organized knowledge even from relatively disorganized instruction, such as exemplar-only instruction. In other words, a self-motivated professional learning style might enable learners to attain organized knowledge in any learning situation, at least for a time. In real-world settings, professional learners are embedded in professional communities, where they share professional values with other individuals in a context of daily interaction (Borko, 2004; Goodwin, 1994, 1997). These daily professional interactions could constitute mere exposure to exemplars and might enhance self-motivated learners' professional vision. Laboratory studies have also found that some participants can distill explicit rules during training (Nosofsky \& Palmeri, 1997, 1998). Future studies should examine the link between participant motivation to learn and the effects of mere exposure to exemplars.

\subsection{Effects of Authentic Recorded Practice on Real-World Professional Vision}

In the same vein, mere exposure to authentic recorded practice might be effective for self-motivated professional learners. After the training, the control group (who did not receive declarative knowledge nor expert commentary) showed an improvement in professional vision with significant tendency (Figure 3). Previous studies suggest that authentic video might help individuals to develop their professional vision (Little et al., 2003; Sherin \& Han, 2004; Star \& Strickland, 2008). Although there was considerable variability in the control group in terms of who showed such a beneficial effect during training (Figure 3), self-motivated learners might be able to extract explicit rules from an authentic video tape depicting a therapy session.

\subsection{Practical Implications of the Present Findings}

Our study has two key findings. First, the development of professional vision initially requires provision of declarative knowledge, and subsequently, further provision of many exemplars, but the converse is not true. Professional training programs should at initial stages focus on novices' declarative knowledge. Novices who attain essential declarative knowledge should then start practical training, as in many medical training programs 
(e.g., Crowley et al., 2003; Naghshineh et al., 2008). Without declarative knowledge, no training program can assure professional development.

Second, self-motivated professional learners are able to extract organized knowledge from experts' comments and authentic video tapes. Professional training programs should seek to nurture such a self-motivated attitude with regards to professional vision. Most professional training programs have learning communities that involve membership and shared emotional connections (e.g., Cohen et al., 2003; Putnam \& Borko, 2000). Such learning communities might work to foster motivation.

\subsection{Limitations}

Our study has at least six limitations. First, our participants were very intelligent (Kamizato, 2009; Norcross et al., 1998). Our findings might not be applicable to professional learners who are self-motivated but not intelligent. Second, our participants were limited only to clinical psychologists and candidates. Hence, the applicability of our findings to other real-world forms of professional vision is unclear (e.g., Chi et al., 1981; De Groot, 1978; Hartswood et al., 2002). Third, instruction and evaluation in the present study were from a SFBT perceptive (Berg \& de Shazer, 2007/2008; Gingerich \& Eisengart, 2000; Hasegawa et al., 2002; Hoyt \& Berg, 2006), such that similar instruction from different disciplines (e.g., Carpenter et al., 2008; Henry et al., 1993; Trepka et al., 2004) might produce different outcomes. Fourth, our study did not include follow-up assessment, such that long-term training effects remain unclear. Fifth, E and control group participants completed the present experiment in less time than did those of the $\mathrm{DE}$ and $\mathrm{D}$ groups, because the former groups did not receive declarative knowledge-based training. Time might have affected their performance and outcomes. Sixth, assessment measures of outcome were not standardized, although these have been used elsewhere (Kersting, 2008; Star \& Strickland, 2008; Stürmer et al., 2013; Van Es \& Sherin, 2008).

\subsection{Conclusions}

Our study is the first to apply instance theory to development of real-world professional vision, at least our knowledge. As expected (Logan, 2002; Palmeri et al., 2004), provision of declarative knowledge with exemplars enhanced the quality of novices' professional vision while narrowing scope of the vision, in the clinical psychology field. However, in contrast to what instance theory predicts, provision of exemplars only also worked to enhance professional vision quality within a limited time. Provision of declarative knowledge with exemplars appears to provide the best model for training programs for both self-motivated professional learners (Borko, 2004; Cohen et al., 2003; Peterson et al., 2011) and general learners (Erickson \& Kruschke, 2002; Nosofsky \& Palmeri, 1998). Provision of exemplars only could be effective for self-motivated learners (Grossman et al., 2001; Stein et al., 1999) for a short term but not general learners (Logan, 1988; Tanaka et al., 2005). Their motivation might enable such learners to extract organized knowledge from insufficient information. Professional education programs should provide declarative knowledge with exemplars through their curriculums and should seek to culture novices' motivation regularly through their learning communities. Future studies should examine the links between participant motivation and mere exposure effects.

\section{Acknowledgements}

Our study was funded by a research grant from the Japanese Association for Graduate Programs in Clinical Psychology (Heisei22B). We appreciate all experts and novices for their participation and Dr. Tai Kurosawa for his insightful feedback on our draft.

\section{References}

Berg, I. K., \& de Shazer, S. (Producer). (2008). I want to want to...: A brief family therapy center the home of solution-focused brief therapy [Motion picture] (Trans. S. Tamama). Japan: Counseling SoFT. Original video was produced in 2007

Borko, H. (2004). Professional development and teacher learning: Mapping the terrain. Educational researcher, 33(8), 3-15. http://dx.doi.org/10.3102/0013189X033008003

Carpenter, T. P., Fennema, E., \& Franke, M. L. (1996). Cognitively guided instruction: A knowledge base for reform in primary mathematics instruction. The Elementary School Journal, 3-20. http://dx.doi.org/10.1086/461846

Carpenter, J., Escudero, V., \& Rivett, M. (2008). Training family therapy students in conceptual and observation skills relating to the therapeutic alliance: An evaluation. Journal of Family Therapy, 30(4), 411-424. http://dx.doi.org/10.1111/j.1467-6427.2008.00442.x 
Chi, M. T., Feltovich, P. J., \& Glaser, R. (1981) Categorization and representation of physics problems by experts and novices. Cognitive Science, 5, 121-52. http://dx.doi.org/10.1207/s15516709cog0502_2

Christensen, A., \& Jacobson, N. S. (1994). Who (or what) can do psychotherapy: The status and challenge of $\begin{array}{llll}\text { nonprofessional therapies. } & \text { Psychological } & \text { science, } & 5(1),\end{array}$ http://dx.doi.org/10.1111/j.1467-9280.1994.tb00606.x

Cohen, D. K., Raudenbush, S. W., \& Ball, D. L. (2003). Resources, instruction, and research. Educational Evaluation and Policy Analysis, 25(2), 119-142. http://dx.doi.org/10.3102/01623737025002119

Crowley, R. S., Naus, G. J., Stewart III, J., \& Friedman, C. P. (2003). Development of visual diagnostic expertise in pathology-an information-processing study. Journal of the American Medical Informatics Association, 10, 39-51. http://dx.doi.org/10.1197/jamia.M1123

De Groot, A. D. (1978). Thought and choice in chess (Vol. 4). Walter de Gruyter.

Erickson, M. A., \& Kruschke, J. K. (2002). Rule-based extrapolation in perceptual categorization. Psychonomic Bulletin \& Review, 9(1), 160-168. http://dx.doi.org/10.3758/BF03196273

Foundation of the Japanese Certification Board for Clinical Psychologists. (2004). Rinshosinrishi ni narutameni dai Jyu ban [To become a clinical psychologist (10th Ed.)]. Tokyo: Seishinshobo.

Gingerich, W. J., \& Eisengar, S. (2000). Solution-focused brief therapy: A review of the outcome research. Family Process, 39, 477-498. http://dx.doi.org/10.1111/j.1545-5300.2000.39408.x

Goodwin, C. (1994). Professional vision. American anthropologist, 96(3), 606-633. http://dx.doi.org/10.1525/aa.1994.96.3.02a00100

Goodwin, C. (1997). The blackness of black: Color categories as situated practice. Natoasi Series of Computer and System Sciences, 160, 111-142.

Grossman, P., Wineburg, S., \& Woolworth, S. (2001). Toward a theory of teacher community. The Teachers College Record, 103(6), 942-1012. http://dx.doi.org/10.1111/0161-4681.00140

Hasegawa, K., Wakashima, K., Sato, K., Ikuta, M., Misawa, F., \& Kubo, J. (2002). Jireidemanabu kazokuryoho tankiryoho monogatariryoho [Case-based learning of family, brief, and narrative therapies]. Tokyo: Kanekoshobo.

Hartswood, M., Procter, R., Rouncefield, M., \& Slack, R. (2002). Performance management in breast screening: A case study of professional vision. Cognition, Technology \& Work, 4(2), 91-100. http://dx.doi.org/10.1007/s101110200008

Henry, W. P., Strupp, H. H., Butler, S. F., Schacht, T. E., \& Binder, J. L. (1993). Effects of training in time-limited dynamic psychotherapy: Changes in therapist behavior. Journal of Consulting and Clinical Psychology, 61(3), 434-440. http://dx.doi.org/ 10.1037/0022-006X.61.3.434

Hoyt, M. F., \& Berg, I. K. (2006). Case studies in couple and family therapy. In M. F. Hoyt (Ed.), The handbook of constructive therapies: Innovative approaches from leading practitioners (pp. 214-238). [T. Kodama, Trans.]. Tokyo: Kongoshuppan (Original work published 1998).

Kamizato, I (2009). Shiteiko no genjyo nit suite [Current Situation of the accredited clinical psychology program]. The Japanese Association for Graduate Programs in Clinical Psychology, 6(1), 3. (in Japanese)

Kemp, N. T., \& Mallinckrodt, B. (1996). Impact of professional training on case conceptualization of clients with a disability. Professional Psychology: Research and Practice, 27(4), 378-385.http://dx.doi.org/ 10.1037/0735-7028.27.4.378

Kersting, N. (2008). Using video clips of mathematics classroom instruction as item prompts to measure teachers' knowledge of teaching mathematics. Educational and Psychological Measurement, 68(5), 845-861. http://dx.doi.org/ 10.1177/0013164407313369

Little, J. W., Gearhart, M., Curry, M., \& Kafka, J. (2003). Looking at student work for teacher learning, teacher community, and school reform. Phi Delta Kappan, 85(3), 184-192.

Logan, G. D. (1988). Toward an instance theory of automatization. Psychological Review, 95(4), 492-527. http://dx.doi.org/10.1037/0033-295X.95.4.492 
Logan, G. D. (2002). An instance theory of attention and memory. Psychological Review, 109(2), 376-400. http://dx.doi.org/10.1037/0033-295X.109.2.376

Microsoft Corporation (Producer) (2009). Wild life sample video in the Windows 7 home premium edition. Redmond. WA: Microsoft Corporation.

Naghshineh, S., Hafler, J. P., Miller, A. R., Blanco, M. A., Lipsitz, S. R., Dubroff, R. P., ... \& Katz, J. T. (2008). Formal art observation training improves medical students' visual diagnostic skills. Journal of General Internal Medicine, 23(7), 991-997. http://dx.doi.org/10.1007/s11606-008-0667-0

Nesbit, J. C., \& Adesope, O. O. (2006). Learning with concept and knowledge maps: A meta-analysis. Review of Educational Research, 76, 413-448. http://dx.doi.org/ 10.3102/00346543076003413

Norcross, J. C., Sayette, M. A., Mayne, T. J., Karg, R. S., \& Turkson, M. A. (1998). Selecting a doctoral program in professional psychology: Some comparisons among $\mathrm{PhD}$ counseling, $\mathrm{PhD}$ clinical, and $\mathrm{PsyD}$ clinical psychology programs. Professional Psychology: Research and Practice, 29(6), 609-614. http://dx.doi.org/ 10.1037/0735-7028.29.6.609.

Nosofsky, R. M., \& Palmeri, T. J. (1997). An exemplar-based random walk model of speeded classification. Psychological Review, 104(2), 266-300. http://dx.doi.org/10.1037/0033-295X.104.2.266

Nosofsky, R. M., \& Palmeri, T. J. (1998). A rule-plus-exception model for classifying objects in continuous-dimension spaces. Psychonomic Bulletin \& Review, 5(3), 345-369. http://dx.doi.org/10.3758/BF03208813

Palmeri, T. J. (1997). Exemplar similarity and the development of automaticity. Journal of Experimental Psychology: Learning, Memory, and Cognition, 23(2), 324. http://dx.doi.org/10.1037/0278-7393.23.2.324

Palmeri, T. J., Wong, A. C., \& Gauthier, I. (2004). Computational approaches to the development of perceptual expertise. Trends in cognitive sciences, 8(8), 378-386. http://dx.doi.org/10.1016/j.tics.2004.06.001

Peterson, R. L., Vincent, W. L., \& Fechter-Leggett, M. (2011). The necessary common knowledge approach to broad and general education for professional psychologists. Training and Education in Professional Psychology, 5(1), 9-14. http://dx.doi.org/10.1037/a0022524

Putnam, R. T., \& Borko, H. (2000). What do new views of knowledge and thinking have to say about research on teacher learning? Educational researcher, 29(1), 4-15.

Rausch, J. R., Maxwell, S. E., \& Kelley, K. (2003). Analytic methods for questions pertaining to a randomized pretest, posttest, follow-up design. Journal of Clinical Child \& Adolescent Psychology, 32, 467-486. http://dx.doi.org/10.1207/S15374424JCCP3203_15

Simon, M. A., \& Schifter, D. (1991). Towards a constructivist perspective: An intervention study of mathematics teacher development. Educational Studies in Mathematics, 22(4), 309-331. http://dx.doi.org/10.1007/BF00369293

Schneider, M., Rittle-Johnson, B., \& Star, J. R. (2011). Relations among conceptual knowledge, procedural knowledge, and procedural flexibility in two samples differing in prior knowledge. Developmental psychology, 47(6), 1525-1538. http://dx.doi.org/ 10.1037/a0024997

Sherin, M. G., \& Han, S. Y. (2004). Teacher learning in the context of a video club. Teaching and Teacher Education, 20(2), 163-183. http://dx.doi.org/10.1016/j.tate.2003.08.001

Sherin, M. G., \& van Es, E. A. (2009). Effects of video club participation on teachers' professional vision. Journal of Teacher Education, 60(1), 20-37. http://dx.doi.org/ 10.1177/0022487108328155

Star, J. R., \& Strickland, S. K. (2008). Learning to observe: Using video to improve preservice mathematics teachers' ability to notice. Journal of Mathematics Teacher Education, 11(2), 107-125. http://dx.doi.org/10.1007/s10857-007-9063-7

Stein, D. M., \& Lambert, M. J. (1995). Graduate training in psychotherapy: Are therapy outcomes enhanced?. Journal of Consulting and Clinical Psychology, 63(2), 182-196. http://dx.doi.org/10.1037/0022-006X.63.2.182

Stein, M. K., Smith, M. S., \& Silver, E. A. (1999). The development of professional developers: Learning to assist teachers in new settings in new ways. Harvard educational review, 69(3), 237-270. 
Stürmer, K., Könings, K. D., \& Seidel, T. (2013). Declarative knowledge and professional vision in teacher education: Effect of courses in teaching and learning. British Journal of Educational Psychology, 83, 467-483. http://dx.doi.org/ 10.1111/j.2044-8279.2012.02075.x

Tanaka, J. W., Curran, T., \& Sheinberg, D. L. (2005). The training and transfer of real-world perceptual expertise. Psychological Science, 16(2), 145-151. http://dx.doi.org/10.1111/j.0956-7976.2005.00795.x

Takano, Y., \& Tanno, Y. (2008) Rumination-Reflection Questionnaire Nihongoban sakusei no kokoromi [Development of Japanese-version Rumination-Reflection Questionnaire]. Personality Kenkyu, 16, 259-261. http://dx.doi.org/10.2132/personality.16.259

Trapnell, P. D., \& Campbell, J. D. (1999). Private self-consciousness and the five-factor model of personality: Distinguishing rumination from reflection. Journal of Personality and Social Psychology, 76, 284-304. http://dx.doi.org/ 10.1037/0022-3514.76.2.284

Trepka, C., Rees, A., Shapiro, D. A., Hardy, G. E., \& Barkham, M. (2004). Therapist competence and outcome of cognitive therapy for depression. Cognitive Therapy and Research, 28(2), 143-157. http://dx.doi.org/10.1023/B:COTR.0000021536.39173.66

Van Es, E. A., \& Sherin, M. G. (2002). Learning to notice: Scaffolding new teachers' interpretations of classroom interactions. Journal of Technology and Teacher Education, 10, 571-96.

Van Es, E. A., \& Sherin, M. G. (2008). Mathematics teachers' "learning to notice" in the context of a video club. Teaching and Teacher Education, 24, 244-276. http://dx.doi.org/10.1016/j.tate.2006.11.005

Van Gog, T., Paas, F., \& Van Merriënboer, J. J. G. (2006). Effects of process-oriented worked examples on troubleshooting transfer performance. Learning and Instruction, 16(2), 154-164. http://dx.doi.org/10.1016/j.learninstruc.2006.02.003

\section{Appendix A}

\section{Conceptual Maps of Solution-Focused Brief Therapy}

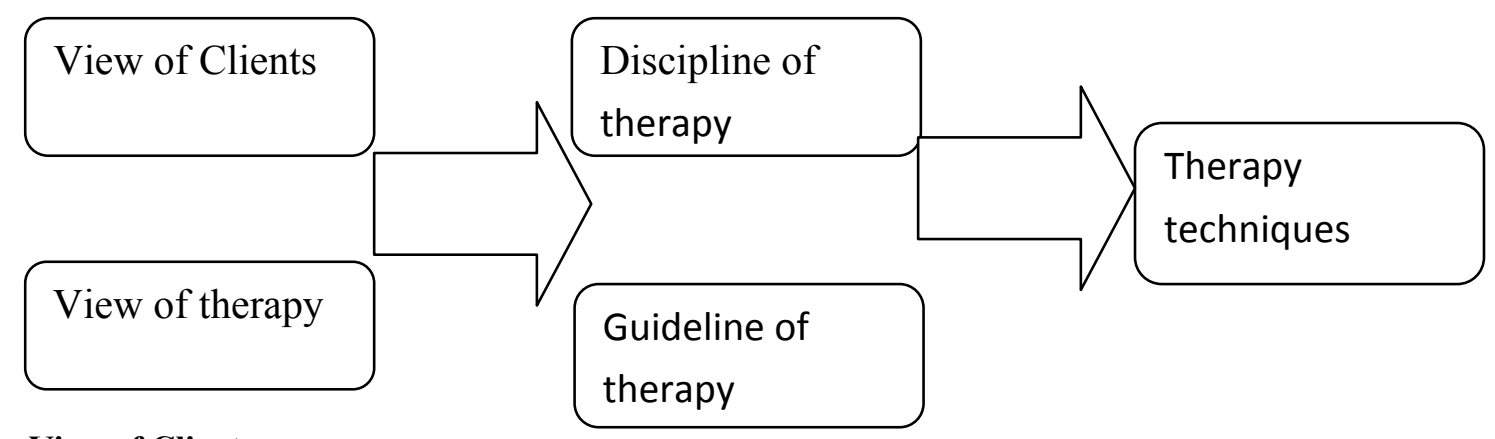

\section{View of Clients}

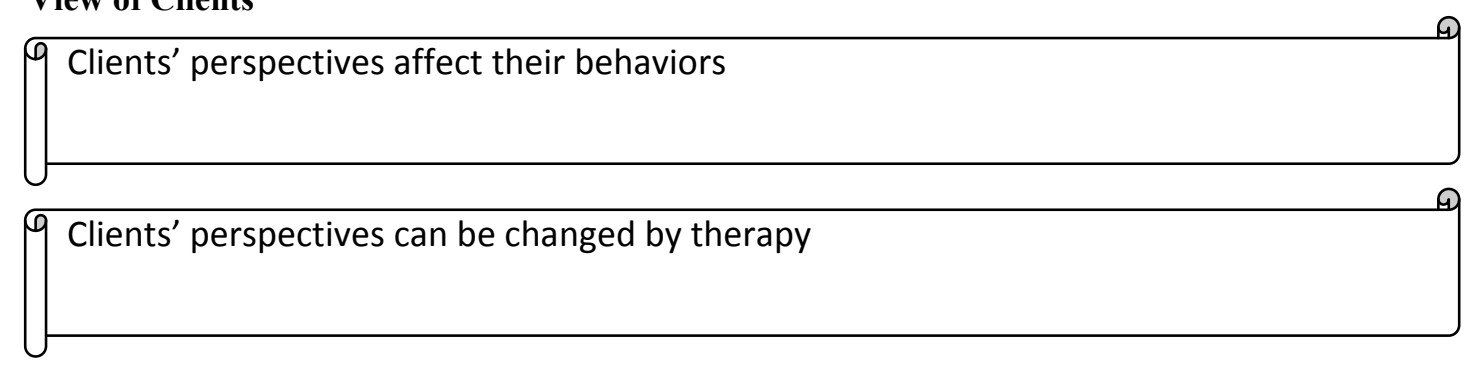

\section{View of therapy}

9 Therapists focus on clients' solutions rather than their problems, and continue to communicate with them.

9 Therapists focus on small solutions [goals]. (This is because a small solution can naturally create more solutions.) 


\section{Discipline of therapy}

91 The solution (goal) of the therapy needs to be expressed concretely, needs to have importance for clients, and can be achieved by them.

2 If a behavior orients clients to their solution, do the behavior more.
3 If a behavior distracts them from their solution, change the behavior.

\section{Guideline of therapy}

1 Move a conversation forward

2 Listen carefully for detail

3 Feedback

\section{Therapy techniques}

1 Miracle question

2 Exception

3 Coping question

4 Scaling question

\section{Appendix B}

\section{Basic two questions}

\begin{tabular}{|c|c|}
\hline Problem types & Choices \\
\hline $\begin{array}{l}\text { 1. A man comes to a therapy room about } \\
\text { his adolescent son with delinquent } \\
\text { behaviors. Based on the } \\
\text { solution-focused approach, a counselor } \\
\text { generally gives feedback to the man in } \\
\text { the following way: }\end{array}$ & $\begin{array}{l}\text { a. Do your son's friends reinforce his delinquent } \\
\text { behaviors? } \\
\text { b. I appreciate you, because you are seriously thinking } \\
\text { about your son's problems as his father. } \\
\text { c. Please tell me more detail about your son during his } \\
\text { early childhood. } \\
\text { d. I think that your son's future is promising. }\end{array}$ \\
\hline 2. The exception, as a technical term, is & $\begin{array}{l}\text { a. How clients would notice the miracle through } \\
\text { several actions and behaviors, if the miracle } \\
\text { happened. }\end{array}$ \\
\hline
\end{tabular}


b. The situation where problems do not occur.
c. How clients have managed their problems.
d. The clients' state, ranging between 1 to 10 .

Note. Based on the solution-focused approach, the answers of problem 1 and 2 are both "b".

\section{Copyrights}

Copyright for this article is retained by the author, with first publication rights granted to the journal.

This is an open-access article distributed under the terms and conditions of the Creative Commons Attribution license (http://creativecommons.org/licenses/by/3.0/). 